Aquaculture

Article In Press

Acceptation date : January 2020

https://doi.org/10.1016/..aquaculture.2020.734986

https://archimer.ifremer.fr/doc/00604/71623/

\title{
Genetic relationship between koi herpesvirus disease resistance and production traits inferred from sibling performance in Amur mirror carp
}

\author{
Zhao Jinfeng 1, ${ }^{*}$, Prchal Martin ${ }^{1}$, Palaiokostas Christos ${ }^{2,3}$, Houston Ross D. ${ }^{3}$, Kause Antti ${ }^{4}$, \\ Vandeputte Marc ${ }^{5,6}$, Vergnet Alain ${ }^{6}$, Bugeon Jérôme ${ }^{7}$, Bestin Anastasia ${ }^{8}$, Veselý Tomáš ${ }^{9}$, \\ Pokorová Dagmar ${ }^{9}$, Piačková Veronika ${ }^{1}$, Pojezdal Lubomír ${ }^{9}$, Genestout Lucie ${ }^{10}$, Gela David ${ }^{1}$, \\ Kroupová Hana K. ${ }^{1}$, Kocour Martin ${ }^{1}$
}

1 University of South Bohemia in České Budějovice, Faculty of Fisheries and Protection of Waters, South Bohemian Research Center of Aquaculture and Biodiversity of Hydrocenoses, Zátiší 728/II, 389 25 Vodňany, Czech Republic

2 Department of Animal Breeding and Genetics, Swedish University of Agricultural Sciences, Box 7090, 75007 Uppsala, Sweden

${ }^{3}$ The Roslin Institute and Royal (Dick) School of Veterinary Studies, University of Edinburgh, Easter Bush, Midlothian, EH25 9RG, Scotland, United Kingdom

${ }^{4}$ Natural Resources Institute Finland (Luke), Biometrical Genetics, FI-31600 Jokioinen, Finland

${ }^{5}$ GABI, INRA, AgroParisTech, Université Paris-Saclay, F-78350 Jouy-en-Josas, France

6 Ifremer, Chemin de Maguelone, F-34250 Palavas-les-Flots, France

7 LPGP, INRA, F-35000 Rennes, France

8 SYSAAF, LPGP/INRA, Campus de Beaulieu, F-35042 Rennes, France

9 Veterinary Research Institute, Hudcova 70, Brno 62100, Czech Republic

10 LABOGENA-DNA, 78350 Jouy-en-Josas, France

* Corresponding author : Jinfeng Zhao, email address : izhao@frov.jcu.cz

\begin{abstract}
:
Koi herpesvirus disease (KHVD) is currently the most serious threat to global carp farming. Prevention is a sensible strategy for tackling this disease and improved genetic resistance of carp strains is a desirable breeding goal. To study the potential for multitrait selection, the objective of the current study was to estimate the genetic correlations between KHVD resistance and production traits in Amur mirror carp. A total of 1500 fingerlings from four factorial crosses of five dams and ten sires were challenged with Koi herpesvirus $(\mathrm{KHV})$. Juvenile growth-related traits were collected on the same individuals before the challenge test. Production traits were measured on siblings of the challenged population at different life stages (yearling to market size). The estimated heritability for resistance to KHVD was $0.43 \pm 0.08$ on the observed scale and $0.72 \pm 0.13$ on the underlying liability scale. Most genetic correlations between KHVD resistance and important production traits were insignificant, showing that selection for improved production traits would not increase susceptibility to KHV and vice versa. However, resistance to KHVD was negatively correlated with Fulton's condition factor (FC) after the second overwintering and relative head length $(\mathrm{RHL})$, relative body height $(\mathrm{RBH})$ and relative body width (RBW) from the second growing season to the market size, with a more prolonged body shape of Amur mirror carp (genes from Amur wild
\end{abstract}


scaly carp, Cyprinus rubrofuscus) being associated with higher KHVD resistance. Intermediate favorable genetic correlations between KHVD resistance and log-log residuals of headless carcass yield $(0.37 \pm 0.14)$ and fillet yield $(0.44 \pm 0.13)$ at market size suggested that selection for improved yields of edible body parts might indirectly lead to a slight improvement in KHVD resistance and vice versa.

\section{Highlights}

Heritability for Koi herpesvirus disease (KHVD) resistance was high. Most genetic correlations between KHVD resistance and important production traits were insignificant. KHVD resistance was significantly genetically correlated to body shape traits and slaughter yields.

Keywords : Common carp, KHVD, Body shape traits, Slaughter yields, Heritability, Genetic correlation 


\section{Introduction}

Common carp (Cyprinus carpio) is one of the most important cultured fish species globally. However, carp farming faces serious challenges due to disease outbreaks (Haenen et al, 2004; Ødegård et al., 2010; Adamek et al,, 2018; Su and Su, 2018; Adamek et al., 2019). Currently, the most serious one is the koi herpesvirus disease (KHVD) that is ca'sed by Cyprinid herpesvirus-3 (CyHV-3), also called Koi herpesvirus (KHV). KHVD outbre ak have been reported both in European and Asian countries (Haenen et al., 2004; Rakus et al., ?013). The severity of KHVD is pinpointed by its listing as a notifiable disease by the Tur ntan Union (Taylor et al., 2010) and the World Organization for Animal Health (OIE, 2ni8). 'lie disease occurs most commonly at water temperatures between $17^{\circ} \mathrm{C}$ and $26^{\circ} \mathrm{C} / \mathrm{H}_{\mathrm{c}}$ 'nen et al., 2004). Morbidity is often $100 \%$, but mortality can vary due to different factors . nd is more likely to occur at higher temperatures $\left(23^{\circ} \mathrm{C}\right.$ and $\left.28^{\circ} \mathrm{C}\right)$ (Hedrick et al., 200؟, Uasa et al, 2008). Therefore, looking to prevent KHVD via selective breeding to produce raw of carp with increased genetic resistance is important for the long-term sustainability of $\iota \cdot r p$ aquaculture.

Aquaculture breeding pr gra ns are increasingly focusing on genetic improvement of disease resistance (Gjedrem and R Jbinson, 2014; Yáñez et al., 2014; Gjedrem and Rye, 2018; Robledo et al., 2018). Previous studies have laid the foundation for breeding of KHV-resistant carp strains and have shown that breeding programs could produce carp strains with high level of resistance (Shapira et al., 2005; Piačková et al., 2013; Tadmor-Levi et al., 2017; Palaiokostas et al., 2018). Estimation of genetic correlations between resistance to KHVD and other production traits that may be included in breeding goals, such as growth, body composition and fish welfare traits is of paramount importance. Most evaluations of genetic correlation of disease resistance with other 
traits in fish have been focused on growth-related traits, particularly in salmonids (e.g. Yáñez et al., 2016; Flores-Mara et al., 2017; Barría et al., 2019; Gjerde et al., 2019). Prior results demonstrated different genetic relationships between resistance to disease and growth. Therefore, genetic correlations are necessary to be known for each fish species before systematic selective breeding program.

The main aim of this study was to estimate genetic correlations of KHVD resistance with other important production traits in Amur mirror carp from yearlings to . narket size. Such knowledge will assist in developing a sustainable breeding program for s.n $^{-}$tic improvement of disease resistance alongside multiple production traits.

\section{Materials and methods}

\subsection{Ethics statement}

The entire experiment was performed $\mathrm{t}$. accordance with the law on the protection of animals against cruelty (Act No. 246/1992 rol rf the Czech Republic) upon its approval by the expert committee of the Institutional A. imai Care and Use Committee (IACUC). All people conducting the trait measurements and $c a^{1}$ enge test were qualified to conduct and manage such kind of experiments on the live a imlals.

\subsection{Establishment and rearing of experimental stocks}

The details of the stocks have been described previously (Palaiokostas et al., 2018 and Prchal et al., 2018ab). In brief, an experimental population of Amur mirror carp was established at the hatchery of Faculty of Fisheries and Protection of Waters of University of South Bohemia in České Budějovice, Vodňany, Czech Republic in May 2014 from artificial spawning according to Vandeputte et al. (2004) using four factorial crosses of five dams and ten sires (20 dams and 40 
sires were used in total) allowing up to 200 full-sib families. Randomly sampled progenies from each cross were pooled using approximately equal total volume and stocked into nursery earthen ponds at stocking density of 150,000 larvae / ha. Fish were then reared under semi-intensive pond conditions through the first growing season until October 2014. Following pond harvest a subset of the stock was used for KHVD challenge test (see below). Prior to the test, fish were phenotyped for growth-related traits. In addition, siblings of the challenged stock were grown up to the market size. Stocking density was 6000 ind./ha (mean we. ${ }_{-3}$ ht of $336.1 \mathrm{~g}$, coefficient of variation of $19.2 \%$ ) during the second growing season and $50 n$. ha (mean weight of $1910 \mathrm{~g}$, coefficient of variation of 14.6\%) during the last (third) grc ving season (see box-plots for weight of experimental stocks in S1 figure). The aforemention 3000 fish were individually tagged using Passive Integrated Transponders (PITs) and +'.er phenotyped for the main production traits after each growing season and each over int ring. At the end of the third growing season, the fish were slaughtered and phenotyped fo nrocessing traits.

\subsection{KHVD challenge test}

A total of 1500 fish were take: $?$; random and PIT-tagged and a sample of fin tissue was taken in autumn 2014 for subseq $:$ m DNA analysis (parentage allocation and genomic analysis). These fish were then acclimatized together with Koi carp $(n=215)$ for five days at water temperature of $22^{\circ} \mathrm{C}$ and bathed in FMC solution (formalin, malachite green, methylene blue using a dose of 2 $\mathrm{mL}$ per $100 \mathrm{~L}$ of water) only for experimental fish to eliminate ectoparasites. Soon after, the fish were transferred to the Veterinary Research Institute (VRI) in Brno in order to perform the KHVD challenge test.

The experimental procedure was the same as described in Palaiokostas et al. (2018). Cohabitation challenge protocol was performed in a tank of $1.4 \mathrm{~m}^{3}$ with recirculation and biological filtration. 
20 fish out of the Koi carp received an intraperitoneal injection with KHV culture established according to standardized protocol by Piačková et al. (2013) and were cohabited with Amur mirror carp and the rest of Koi carps. Mortality of individual fish was recorded twice a day for a period of 35 days post infection (dpi) when mortalities were negligible. Resistance was recorded as 0 for dead fish and 1 for surviving fish. Presence of KHV on samples of dead fish $(n=5)$ was confirmed in seven time points from 10 to 35 dpi by nested PCR as described by Pokorova et al. (2010).

\subsection{Parentage assignment of experimental stocks}

Parentage assignment of challenged fish was done on $1^{-n}, \mathrm{~J}$ fish by SNP genotype data $(12,311$ SNPs grouped in 50 linkage groups) using $\mathrm{R}$ snf "ar version 3.6.1 (R Core Team, 2019) with hsphase package version 2.0.2 (Ferdosi et 1., 2014). Parentage assignment of the second and the third year fish (production traits) was based on the analysis of 12 microsatellite loci and performed using the AccurAssign $₫ \wedge \mathrm{ftv}$ are, applying a maximum-likelihood method (Boichard et al., 2012). For more details see I $^{-}$laiokostas et al. (2018) and Prchal et al. (2018b).

\subsection{Production traits reci raing on siblings}

Juvenile growth-related traits (body weight - BW and Fulton's condition factor - FC) were measured in the same tagged individuals $(n=1500)$ from the challenge test. Each individual was weighed (to the nearest $0.01 \mathrm{~g}$ ) and measured for standard length (SL) (to the nearest $0.1 \mathrm{~mm}$ ). $\mathrm{FC}$ was calculated according to formula: $\mathrm{FC}=10^{5} * \mathrm{BW} / \mathrm{SL}^{3}$.

After the first overwintering (March 2015), a random sample of 3000 siblings coming from the same stock as the disease challenged animals (being reared in the same pond, i.e. identical 
environmental conditions) were phenotyped. Recorded traits included standard length (SL), body length (BL), head length (HL), body height (BH), body width (BWI), and body weight (BW). In addition, biometric indices were calculated as follows: relative body height: $\mathrm{RBH}=\mathrm{BH} / \mathrm{SL}$, relative head length: $\mathrm{RHL}=\mathrm{HL} / \mathrm{SL}$ and relative body width: $\mathrm{RBW}=\mathrm{BWI} / \mathrm{SL}$. The survival of those individually tagged fish was recorded before and after the second overwintering period as well as at the end of third growing season (market size). At each of these time points, the following individual traits were recorded: body weight (g), muscic fat by Distell fish fat meter $(\%)$, absolute and relative muscle fat change, weight change ${ }^{\lambda_{\mathbf{I}}}{ }^{\mathrm{r}}$, ssed as specific growth rate (SGR), RBH, RHL, RBW, FC. At the final sampling, the rtural logarithm of the weight of each slaughter body part was calculated and regressed on in logarithm of body weight to obtain growth-independent allometry residuals that fix $\mathrm{t}_{1} \in \mathrm{b}$ as of ratio traits. The $\log$ - $\log$ residuals of headless carcass yield and fillet yield were rec srded as Logr_hl-Carss and Logr_Fill, respectively. Specific details about traits and their cal lation are shown in Prchal et al. (2018ab).

\subsection{Estimation of genetic paran, ters}

The heritability of KHVD res ${ }^{{ }^{c} t}$ nce and genetic correlations between KHVD resistance (1214 fish assigned to a parem $\urcorner$ pair, forming 195 full-sib families) and production traits (1879 fish assigned to a parental pair, forming 199 full-sib families) were estimated using DMU statistical software (Madsen and Jensen, 2013). The following linear animal model was used:

$\boldsymbol{y}=X \boldsymbol{\beta}+Z a+e$,

where $\boldsymbol{y}$ is the vector of the observations of KHVD resistance and production traits, $X$ and $Z$ are the corresponding design matrices for the fixed effects and the additive genetic effects of the animal, $\boldsymbol{\beta}$ is the vector of the fixed effects for KHVD resistance (with mating design - four 
crosses) and production traits (with sex), $\boldsymbol{a}$ is the vector of random animal additive genetic effect that is distributed $\mathrm{N}\left(0, \mathbf{A} \sigma_{a}^{2}\right)$, and $\boldsymbol{e}$ is the vector of the random residual effect that is distributed $\mathrm{N}\left(0, \mathbf{I} \sigma_{e}{ }^{2}\right)$. A is the relationship matrix, $\mathbf{I}$ is an identity matrix, $\sigma_{a}{ }^{2}$ is the additive genetic variance and $\sigma_{e}^{2}$ is the residual variance. Heritability for KHVD resistance was firstly estimated on the observed scale as $h^{2}=\sigma_{\mathrm{a}}{ }^{2} / \sigma_{\mathrm{a}}{ }^{2}+\sigma_{\mathrm{e}}{ }^{2}$. Subsequently, this value was transformed to the underlying normally distributed liability scale using the formula by Dempster and Lerner (1950). All traits were recorded from the same families and had a common pedigree , ${ }^{f}$ amily structure), but KHVD resistance and other performance traits were recorded on diti $m$, nt individuals. As a result, residual covariance was set to zero between these train Estimated genetic correlation was considered significant at $\mathrm{p}<0.05$ when $\left|r_{g}\right|-\mid 1.96 \times$ ค..E. $\mid$ was not zero or less (two-tailed hypothesis) (Coolidge, 2013).

\section{Results}

\subsection{Experimental challenge test}

Fish experimentally infected $w$ ith sHV presented typical clinical and pathological patterns. These symptoms included he ${ }^{\prime}{ }^{\prime}$ oral changes (lethargic, loss of equilibrium and disorientation), pale discoloration of th skin and gills or reddened skin, focal or total loss of epidermis, overproduction of mucus on the skin and gills, sunken eyes, hemorrhages of the skin and fins, and fin erosion. During the 35 days of challenge, mortalities began to appear at 12 dpi, then reached a maximum between 21 and 24 dpi (Figure 1). The percentage of total mortality for the Amur mirror carp was $66 \%$.

3.2. Heritability and genetic correlations amongst KHVD resistance and production traits 
The estimated heritability for resistance to KHVD was moderate $(0.43 \pm 0.08)$ on the observed scale and high $(0.72 \pm 0.13)$ on the underlying liability scale. Genetic correlations between KHVD resistance and important production traits were in general statistically insignificant (Table 1 - 4). However, genetic correlation between FC after the second overwintering and KHVD resistance was significantly different from zero and negative $\left(r_{g}=-0.32 \pm 0.14\right)$. Likewise, genetic correlations between KHVD resistance and biometrical indices (relative head length, relative body height, relative body width) were negative and sig_.ificant when the traits were measured during the period before the second winter until mark + size (Table $3-4$ ) and at the edge of significance for RBW at market size (Table 4). $\mathrm{O}$. the other hand, intermediate positive and significant genetic correlations were found between V.HVD resistance and slaughter yields ( $\log$ - $\log$ residuals of headless carcass yield and 1 "'et yield, respectively) $\left(r_{g}=0.37 \pm 0.14\right.$ and $0.44 \pm 0.13$, respectively). Phenotypic cc rel tions could not be estimated due to the fact that KHVD resistance and other production $\mathrm{L}$ aits were measured on different individuals.

\section{Discussion}

The heritability estimate for 1 si tance to KHVD was high on both observed and the underlying scale $(0.43 \pm 0.08$ and $ぇ \%\llcorner \pm 0.13$, respectively). Ødegård et al. (2010) observed even higher heritability $(0.79 \pm 0.14)$ for KHVD resistance on the underlying scale in common carp. In their case probably high overall mortality of challenged fish (6\% vs. $34 \%$ in our study) and significant survival differences within lower number of full-sib families (91 full-sib families vs. 195 full-sib families) could increase the heritability value. Using a subset of the current data set, heritability of KHVD resistance as measured by survival on the underlying scale for the pedigree and genomic relationship matrix was 0.61 and 0.50, respectively (Palaiokostas et al., 2018). However, we used a different animal model and statistic program that showed a slightly higher pedigree 
heritability (0.72). Similar significant heritability estimates of resistance to diseases have been reported, which demonstrated the feasibility of genetic improvement through selection (e.g. Doan Q. et al., 2017; Shoemaker et al., 2017; Barría et al., 2019; Gjerde et al., 2019). More specifically, there is a strong potential to improve resistance to KHVD by a breeding program. Still, it would be very useful to find a reliable way of selecting resistant candidates (to predict KHVD resistance) without challenging the fish to KHV. Furthermore, challenge tests to diseases are problematic with respect to animal welfare and sometimes even to furth: utilization and rearing of challenged survivor fish as broodstock, which is the cheap hu. ${ }^{2}$ sky solution to select for a disease without need for family information (e.g. KHV i. on the list of notifiable diseases, so challenged fish could not be reared in outer pond conditio:- any more).

In our data, almost all genetic associations betwe $₹ \mathrm{~K}$ IVD resistance and production traits were insignificant. Similar to Ødegård et al. ( $2^{\prime} \cdot 10^{\prime}$, we found no genetic correlation between KHVD resistance and pond survival. So, genei- improvement of KHVD resistance is not genetically related to better general survivabilitv $n$ ihe absence of disease outbreaks. Similarly, we found insignificant genetic correlation between disease resistance and growth-related traits, as has been found in other fishes (e.g. $S_{11}$ erstein et al., 2009; Yáñez et al., 2014; Flores-Mara et al., 2017; Bassini et al., 2019). T1 ${ }^{\circ}$ ineans that selection of fish for growth, the trait typically given the highest weighting in a carp breeding program, should not increase susceptibility of fish to diseases. The absence of significant genetic correlations among commercially important production traits (e.g. growth, \% muscle fat, survival) and KHVD in Amur mirror carp suggested that selective breeding program should not affect the resistance of carp to KHVD and vice versa. Significantly negative genetic correlation was observed between FC after the second overwintering and KHVD resistance, suggesting that selection for lower FC could improve the resistance of fish to that disease. Likewise, RBH, RBW and RHL were significantly negatively 
related to KHVD resistance from the second growing season to the third growing season. This is in accordance with the fact that FC in Amur mirror carp is closely genetically related to the body shape and to relative body height and relative head length (Prchal et al, 2018b). So, such associations implied that Amur mirror carp with typically more prolonged body shape of Amur wild scaly carp, which was used to establish Amur mirror carp (Flajšhans et al., 2015), is well known as one of the most resistant carps to KHVD (Piackova et al., 2013). So, selection for lower FC, RHL, RBW or RBH would indirectly increase KHVD . sistance probably due to the fact that such fish would bear more genes from wild scaly ${ }^{a_{1}} t^{\dagger}$.lat might be responsible for resistance to KHVD and these genes are linked to those re nonsible for prolonged body shape or might show certain pleiotropic effect, similarly like scalu. ss pattern in relation to fitness traits in common carp (Casas et al., 2013). Moreover, si $\mathbf{n}$ election could indirectly further improve slaughter yields at market size as there is + re ationship that prolonged body shape is genetically related to higher dress out traits in comı`on carp (Prchal et al., 2018a). That is why selection of fish for log-log residuals of slaughter iv lds could positively affect KHVD resistance and vice versa.

We should also take into cons. de ration that any selection (e.g. for increased KHVD resistance or dress out yield) that mis't indirectly lead to significant decrease of RHL might also negatively impact the animals welfare. Gills control vital respiration and osmoregulation processes, as such a significant decrease of RHL might impair their function. Moreover, any selection that might indirectly lead to a significant change of less favourable body shape for market acceptance should also be under close monitoring (Haffray et al,, 2012; Fraslin et al, 2018; Prchal et al, 2018a). Therefore, further studies are needed to identify real effect of long-term selective breeding program focused on improved KHVD resistance and/or slaughter yields on body shape and allometry. 


\section{Conclusion}

In conclusion, we identified negative genetic correlations between KHVD resistance and body shape traits, and the favorable genetic correlations between KHVD resistance and slaughter yields. In addition, the absence of significant genetic correlations between other production traits and KHVD resistance indicates that selection for improved production traits is not expected to increase the susceptibility of fish to KHVD and vice versa.

\section{Declaration of competing interest}

The authors declare that they have no conflict of interest.

\section{Author contributions}

MP, DG and MK shared on establ: hitr and on-growing the experimental stock, juvenile phenotyping, PIT tagging, and fin cllp ${ }_{2}$ ing of fish. TV, DP, VP and LP carried out the challenge experiment. JZ, MP, MV, AV, Ib, AB, HKK and MK shared on final trait recordings. CP, RH and LG carried out DNA \& xtractions and parentage assignment. MP introduced JZ to the quantitative genetic anal ssis. JZ and MP estimated the genetic parameters. All authors contributed to drafting the manuscript.

\section{Acknowledgements}

This study is part of the FishBoost project, funded by the European Union under the 7th Framework Programme under grant agreement (613611), project of NAAR (NAZV) (QK1910430) under Ministry of Agriculture of the Czech Republic, and projects Biodiversity 
(CZ.02.1.01/0.0/0.0/16_025/0007370) and PROFISH (CZ.02.1.01/0.0/0.0/16_019/0000869) both under the Ministry of Education, Youth and Sports of the Czech Republic.

\section{References}

Adamek, M., Matras, M., Dawson, A., Piackova, V., Gela, D., Kocour, M., Adamek, J., Kaminski, R., Rakus, K., Bergmann, S.M., Stachnik, M., Reichert, M., Steinhagen, D., 2019. Type I interferon responses of common carp strains with different levels of resistanc ${ }^{+}$to koi herpesvirus disease during infection with CyHV-3 or SVCV. Fish Shellf sh Immunol. 87, 809-819. https $/ /$ doi.org/10.1016/j.fsi.2019.02.022

Adamek, M., Teitge, F., Jung-Schroers, V., Heling, M., Ge`^, L , ’’iackova, V., Kocour, M., Steinhagen, D., 2018. Flavobacteria as secondary pathogens in carp sutiving from koi sleepy disease. J. Fish Dis. 41, 1631-1642. https://doi.org/10.1111/jfd.1287?

Barría, A., Doeschl-Wilson, A.B., Lhorente, J.? , Houston, R.D., Yáñez, J.M., 2019. Novel insights into the genetic relationship between grow $h$ and disease resistance in an aquaculture strain of Coho $\begin{array}{lllll}\text { salmon } \quad \text { (Oncorhynchus } \quad \text { kisutch). } & \text { Aquaculture } & 511, & 734207 .\end{array}$ https:/doi.org/10.1016/j.aqua Ituru.2019.734207

Bassini, L.N., Lhorente, J.P., G jarz ın, M., Bangera, R., Yáñez, J.M., Neira, R., 2019. Genetic parameters for Piscirickettsia,$\imath_{1} \ldots \cdots$ s resistance, sea lice (Caligus rogercresseyi) susceptibility and harvest weight in rainbuw trout (Oncorhynchus mykiss). Aquaculture 510, 276-282. https $/ /$ doi.org/10.1016/j.aquaculture.2019.05.008

Boichard, D., Barbotte, L., Genestout, L., Gabi, U.M.R., Josas, J., Josas, J., 2012. Proceedings, 10.

Casas, L., Szucs, R., Vij, S., Goh, C.H., Kathiresan, P., Németh, S., Jeney, Z., Bercsényi, M., Orbán, L., 2013. Disappearing scales in carps: Re-visiting Kirpichnikov's model on the genetics of scale pattern formation. PLoS One 8. https://doi.org/10.1371/journal.pone.0083327

Coolidge, F.L., 2013. Statistics: a gentle introduction. $3^{\text {rd }}$ edition. Thousand Oaks, CA: Sage, USA. 463 pp. 
Dempster, E.R., Lerner, I.M., 1950. Heritability of Threshold Characters. Genetics 35, 212-36.

Doan Q., K., Vandeputte, M., Chatain, B., Haffray, P., Vergnet, A., Breuil, G., Allal, F., 2017. Genetic variation of resistance to Viral Nervous Necrosis and genetic correlations with production traits in wild populations of the European sea bass (Dicentrarchus labrax). Aquaculture 478, 1-8. https $/ /$ doi.org/10.1016/j.aquaculture.2017.05.011

Ferdosi, M.H., Kinghorn, B.P., van der Werf, J.H.J., Lee, S.H., Gondro, C., 2014. hsphase: An R package for pedigree reconstruction, detection of recombination events, phasing and imputation of half-sib family groups. BMC Bioinformatics 15. https://doi.org/10.1186/1

Flajšhans, M., Gela, D., Kocour, M., Rodina, M., Kašpar, V., Linh ırt, . ., et al., 2015. Amur mirror carp, a recently certified breed of common carp in the Czerh Republic. In: Book of abstracts: 3rd International Conference on Common Carp, pp. 21-23

Flores-Mara, R., Rodríguez, F.H., Bangera, R., Lhorəı' , J P., Neira, R., Newman, S., Yáñez, J.M., 2017. Resistance against infectious pancreatir ner rosis exhibits significant genetic variation and is not genetically correlated with harvest we : oht in rainbow trout (Oncorhynchus mykiss). Aquaculture 479, 155-160. https://doi.org/10.1016/j.ayv ıc ıture.2017.05.042

Fraslin, C., Dupont-Nivet, M., Haf'ra, P., Bestin, A., Vandeputte, M., 2018. How to genetically increase fillet yield in fish: New insig 's from simulations based on field data. Aquaculture 486, 175-183. https //doi.org/10.1716, i.aqı aculture.2017.12.012

Gjedrem, T., Robinson, N .014. Advances by Selective Breeding for Aquatic Species: A Review. Agric. Sci. 05, 1152-1158. https://doi.org/10.4236/as.2014.512125

Gjedrem, T., Rye, M., 2018. Selection response in fish and shellfish: a review. Rev. Aquac. 10, 168-179. https $/ /$ doi.org/10.1111/raq. 12154

Gjerde, B., Boison, S.A., Aslam, M.L., Løvoll, M., Bakke, H., Rey, S., Lillehammer, M., 2019. Estimates of genetic correlations between susceptibility of Atlantic salmon to amoebic gill disease in a bath $\begin{array}{llllll}\text { challenge test and a field test. } & \text { Aquaculture 511, }\end{array}$ https:/doi.org/10.1016/j.aquaculture.2019.734265 
Haenen, O.L.M., Way, K., Bergmann, S.M., Ariel, E., 2004. The emergence of koi herpesvirus and its significance to European aquaculture. Bull. Eur. Assoc. Fish Pathol. 24, 293-307.

Haffray, P., Bugeon, J.Ô., Pincent, C., Chapuis, H., Mazeiraud, E., Rossignol, M.N., Chatain, B., Vandeputte, M., Dupont-Nivet, M., 2012. Negative genetic correlations between production traits and head or bony tissues in large all-female rainbow trout (Oncorhynchus mykiss). Aquaculture 368369, 145-152. https://doi.org/10.1016/j.aquaculture.2012.09.023

Hedrick, R.P., Gilad, O., Yun, S., Spangenberg, J. V., Marty, G.D., Nordhausen, R.W., Kebus, M.J., Bercovier, H., Eldar, A., 2000. A herpesvirus associated with $\mathrm{r}_{\text {as }}$ mırtality of juvenile and adult koi, a strain of common carp. J. Aquat. Anim. Health 1\%, 4. -57. https://doi.org/10.1577/15488667(2000)012<0044:AHAWMM>2.0.CO;2

Madsen, P., Jensen, J., 2013. DMU version 6. Available f־oı · http://dmu.agrsci.dk/DMU/Doc/Current/ dmuv6_guide.5.2.pdf.

Ødegård, J., Olesen, I., Dixon, P., Jeney, Z. Nif sen, H.M., Way, K., Joiner, C., Jeney, G., Ardó, L., Rónyai, A., Gjerde, B., 2010. Gen 'ic analysis of common carp (Cyprinus carpio) strains. II: Resistance to koi herpesvirus and se o ronas hydrophila and their relationship with pond survival. Aquaculture 304, 7-13. https:/'dı: org/10.1016/j.aquaculture.2010.03.017

Piačková, V., Fla jšhans, M., Prkorc ’á, D., Reschová, S., Gela, D., Č́žžek, A., Veselý, T., 2013. Sensitivity of common carp, Cy, rinu s carpio L., strains and crossbreeds reared in the Czech Republic to infection by cypin $\mathrm{d}$ herpesvirus 3 (CyHV-3; KHV). J. Fish Dis. 36, 75-80. https $/ /$ doi.org/10.1111/jfd. 12007

Pokorova, D., Reschova, S., Hulova, J., Vicenova, M., Vesely, T., Piackova, V., 2010. Detection of cyprinid herpesvirus-3 in field samples of common and koi carp by various single-round and nested PCR methods. J. World Aquac. Soc. 41, 773-779. https $/ /$ doi.org/10.1111/j.1749-7345.2010.00419.x

Prchal, M., Bugeon, J., Vandeputte, M., Kause, A., Vergnet, A., Zhao, J., Gela, D., Genestout, L., Bestin, A., Haffray, P., Kocour, M., 2018a. Potential for Genetic Improvement of the Main Slaughter Yields in Common Carp With in vivo Morphological Predictors. Front. Genet. 9. 
https $/ /$ doi.org/10.3389/fgene.2018.00283

Prchal, M., Kause, A., Vandeputte, M., Gela, D., Allamellou, J.M., Kumar, G., Bestin, A., Bugeon, J., Zhao, J., Kocour, M., 2018b. The genetics of overwintering performance in two-year old common carp and its relation to performance until market size. PLoS One 13, 1-17. https $/ /$ doi.org/10.1371/journal.pone.0191624

R Core Team, 2019. R: A language and environment for statistical computing. R Foundation for Statistical Computing, Vienna, Austria. URL https://www.R-project.org/.

Rakus, K., Ouyang, P., Boutier, M., Ronsmans, M., Reschner, A., Vınc. ok, C., Jazowiecka - Rakus, J., Vanderplasschen, A., 2013. Cyprinid herpesvirus 3: an inter stin $६$ virus for applied and fundamental research. Vet. Res. 44, 85. https:// doi.org/10.1186/1297. ? ?10 14-85

Robledo, D., Matika, O., Hamilton, A., Houston, R.D., 2J1ठ. Genome-wide association and genomic selection for resistance to amoebic gill diseas in A antic salmon. G3 Genes, Genomes, Genet. 8, 1195-1203. https://doi.org/10.1534/g3.11' 2r J075

Shapira, Y., Magen, Y., Zak, T., Kotler, M., Hulata, G., Levavi-Sivan, B., 2005. Differential resistance to koi herpes virus (KHV)/carp intersti ia nephritis and gill necrosis virus (CNGV) among common carp (Cyprinus carpio L.) strains and crossbreds. Aquaculture 245, 1-11. https //doi.org/10.1016/j.a., 'lacl iure.2004.11.038

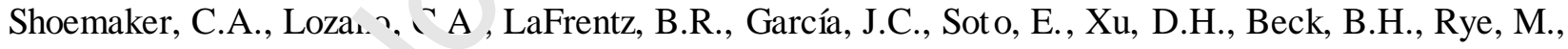
2017. Additive ge. alc variation in resistance of Nile tilapia (Oreochromis niloticus) to Streptococcus iniae and S. agalactiae capsular type Ib: Is genetic resistance correlated? Aquaculture 468, 193-198. https://doi.org/10.1016/j.aquaculture.2016.10.022

Silverstein, J.T., Vallejo, R.L., Palti, Y., Leeds, T.D., Rexroad, C.E., Welch, T.J., Wiens, G.D., Ducrocq, V., 2009. Rainbow trout resistance to bacterial cold-water disease is moderately heritable and is not adversely correlated with growth. J. Anim. Sci. 87, 860-867. https://doi.org/10.2527/jas.2008-1157

Su, H., Su, J., 2018. Cyprinid viral diseases and vaccine development. Fish Shellfish Immunol. 83, 84-95. https:/doi.org/10.1016/j.fsi.2018.09.003 
Tadmor-Levi, R., Asoulin, E., Hulata, G., David, L., 2017. Studying the genetics of resistance to CyHV-3 disease using introgression from feral to cultured common carp strains. Front. Genet. 8, 1-13. https:/doi.org/10.3389/fgene.2017.00024

Taylor, N.G.H., Dixon, P.F., Jeffery, K.R., Peeler, E.J., Denham, K.L., Way, K., 2010. Koi herpesvirus: distribution and prospects for control in England and Wales. J. Fish Dis. 33, 221-230. https $/ /$ doi.org/10.1111/j.1365-2761.2009.01111.x

Vandeputte, M., Kocour, M., Mauger, S., Dupont-Nivet, M., De Guerry D., Rodina, M., Gela, D., Vallod, D., Chevassus, B., Linhart, O., 2004. Heritability estimate, 'or growth-related traits us ing

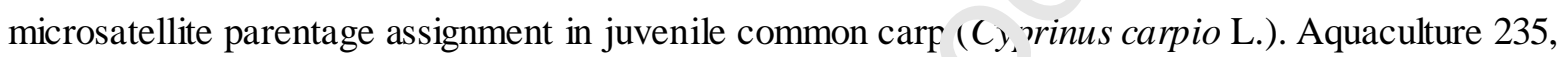
223-236. https://doi.org/10.1016/j.aquaculture.2003.12.010

Yáñez, J.M., Bangera, R., Lhorente, J.P., Barría, A., Oyarzún, ‘ ‘., Neira, R., Newman, S., 2016. Negative genetic correlation between resistance against $F$ :cir ckettsia salmonis and harvest weight in coho salmon $\quad$ (Oncorhynchus $\quad$ kis'tch). $\quad$ Aquaculture $\quad 459, \quad 8-13$. https:/doi.org/10.1016/j.aquaculture. $2^{\top 1} 6.03 .020$

Yáñez, J.M., Lhorente, J.P., Bassini, L.N., Jyarzún, M., Neira, R., Newman, S., 2014. Genetic covariation between resistance $\mathrm{xg}_{n}{ }^{\mathrm{n}} \mathrm{nst}$ both Caligus rogercresseyi and Piscirickettsia salmonis, and body weight in Atlan: : salmon (Salmo salar). Aquaculture 433, 295-298. https:/doi.org/10.116, i.aqı aculture.2014.06.026

Yuasa, K., Ito, T., Sano, M , 2008. Effect of water temperature on mortality and virus shedding in carp experimentally infected with koi herpesvirus. Fish Pathol. 43, 83-85. https $/ /$ doi.org/10.3147/jsfp.43.83 
Figure 1. Daily mortality of fish during the KHV challenge experiment

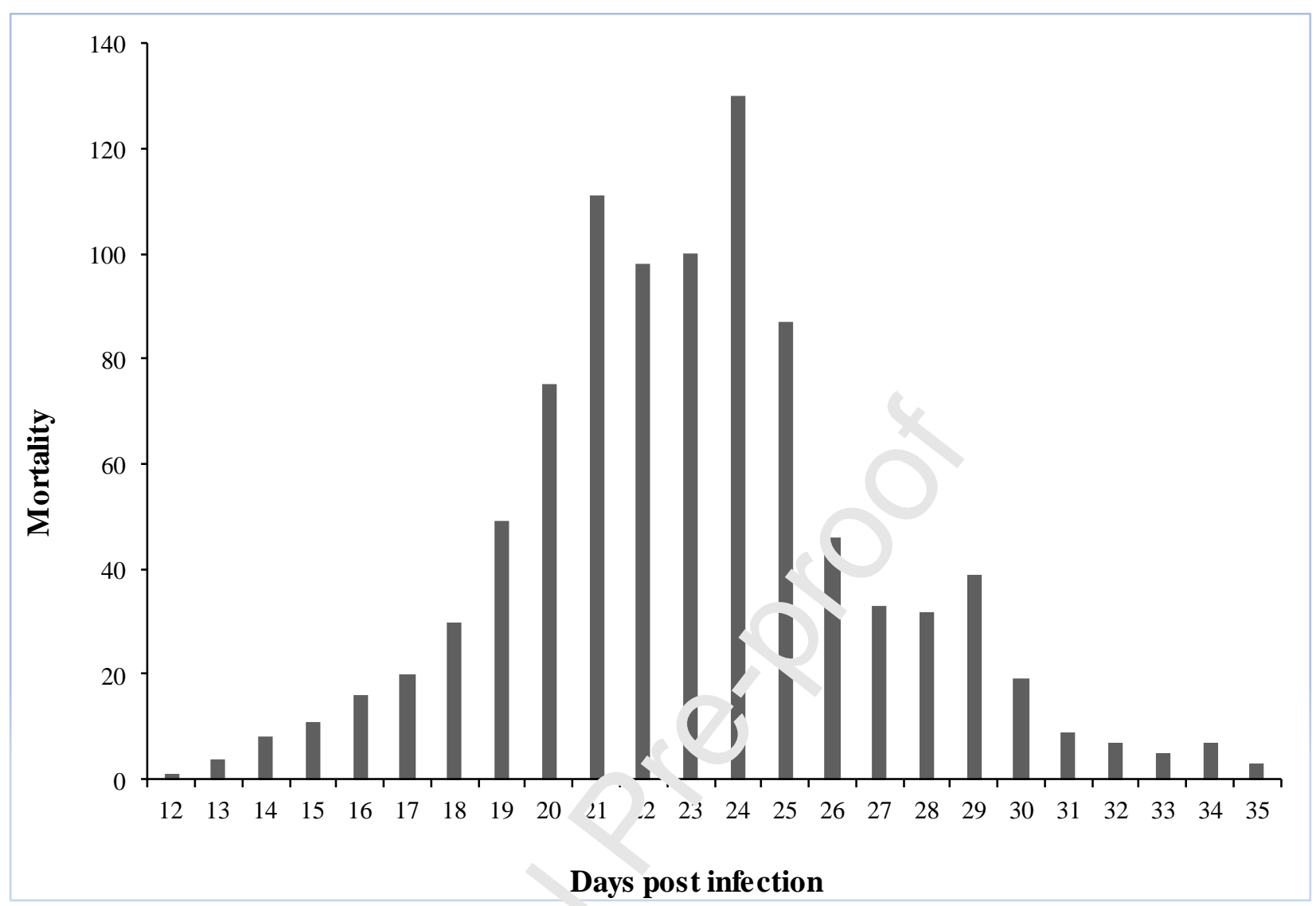


Table 1. Genetic correlations ( \pm standard error) between KHVD resistance and body weight $(\mathrm{BW})$ and condition factor (FC) in challenged fish

\begin{tabular}{cc}
\hline & KHVD resistance \\
\hline BW & $-0.02 \pm 0.18$ \\
FC & $-0.16 \pm 0.17$ \\
\hline
\end{tabular}

Table 2. Genetic correlations ( \pm standard error) between KHVD resista ce and production traits of siblings after the first overwintering

\begin{tabular}{cc}
\hline & MLVD resistance \\
\hline BW & $-\frac{0.06 \pm 0.18}{0.07 \pm 0.17}$ \\
RBH & $-0.26 \pm 0.16$ \\
RBW & $-0.23 \pm 0.19$ \\
$\mathbf{\text { RHL }}$ & $-0.15 \pm 0.21$ \\
\hline
\end{tabular}

$\mathbf{B W}=$ body weight, $\mathbf{F C}=$ Fultol ${ }^{\circ}$ cr ndition factor, $\mathbf{R B H}=$ relative body height, $\mathbf{R B W}=$ relative body width, $\mathbf{R H L}=$ relative head length. 
Table 3. Genetic correlations ( \pm standard error) between KHVD resistance and production traits of siblings related to the second overwintering

\begin{tabular}{|c|c|}
\hline & KHVD resistance \\
\hline Fatch & $-0.17 \pm 0.19$ \\
\hline$\%$ Fatch & $-0.17 \pm 0.19$ \\
\hline SGR & $-0.10 \pm(17$ \\
\hline Winter Surv & $-0.19=0.3$. \\
\hline FC_B & $-\cap .{ }^{\prime} 8 \pm 0.15$ \\
\hline FC_A & $-0.32 \pm 0.14 *$ \\
\hline$\%$ Fat_B & $0.15 \pm 0.16$ \\
\hline \% Fat_A & $0.07 \pm 0.16$ \\
\hline B W_B & $-0.07 \pm 0.17$ \\
\hline $\mathbf{B} \mathbf{W}_{-}$ & $-0.05 \pm 0.17$ \\
\hline RB $^{\prime} 1_{-}$? & $-0.45 \pm 0.13 *$ \\
\hline Rᄂ'H_A & $-0.35 \pm 0.14 *$ \\
\hline$\therefore S W \_B$ & $-0.39 \pm 0.15 *$ \\
\hline RBW_A & $-0.38 \pm 0.15 *$ \\
\hline RHL_B & $-0.39 \pm 0.15 *$ \\
\hline RHL_A & $-0.41 \pm 0.14 *$ \\
\hline
\end{tabular}

$\mathbf{B}=$ the trait was recorded before the second overwintering, $\mathbf{A}=$ the trait was recorded after the second overwintering, Fatch and \% Fatch $=$ absolute and relative fat change, $\mathbf{S G R}=$ specific growth rate, Winter Surv $=$ winter survival, $\mathbf{F C}=$ Fulton's condition factor, $\%$ Fat $=$ muscle fat content, $\mathbf{B W}=$ body weight, $\mathbf{R B} \mathbf{H}=$ relative body height, $\mathbf{R B W}$ $=$ relative body width, $\mathbf{R H L}=$ relative head length. ${ }^{*}$ Confidence limit $\left|r_{g}\right|-\mid 1.96 \times$ S.E. $\mid$ not being zero or less represents significant correlations at $\mathrm{p}<0.05$. 
Table 4. Genetic correlations ( \pm standard error) between KHVD resistance and market size production traits of siblings

\begin{tabular}{cc}
\hline & KHVD resistance \\
\hline Market Surv & $0.19 \pm 0.24$ \\
\% Fat & $0.16 \pm 115$ \\
BC & $-0.20 \pm 0.4$ \\
Logr_hl-Carss & $-0 . .^{0} \pm 0.15$ \\
Logr_Fill & $037 \pm \mathbf{0 . 1 4} *$ \\
RBH & $\mathbf{0 . 4 4} \pm \mathbf{0 . 1 3} *$ \\
RBW & $\mathbf{- 0 . 2 9 \pm 0 . 1 4 *}$ \\
RHL & $-0.26 \pm 0.15$ \\
\hline
\end{tabular}

Market Surv = market size surviv 1, $\therefore$ Fat $=$ muscle fat content, $\mathbf{F C}=$ Fulton's condition factor, $\mathbf{B W}=$ body weight, Logr_hl-Carss $=\log { }_{-}^{1}{ }_{0}$ re__uluals of headless carcass yield, $\mathbf{L o g r} \_$Fill $=\log$-log residuals of fillet y ield, RBH = relative body height, $\mathbf{P}_{\mathbf{b r}}=$ relative body width, $\mathbf{R H L}=$ re lative head length. ${ }^{*}$ Confidence limit $\left|r_{g}\right|-\mid 1.96$ $\times$ S.E. $\mid$ not being zero or less represents significant correlations at $\mathrm{p}<0.05$. 
Highlights:

- Heritability for Koi herpesvirus disease (KHVD) resistance was high.

- Most genetic correlations between KHVD resistance and important production traits were insignificant.

- KHVD resistance was significantly genetically correlated to body shape traits and slaughter yields. 